\title{
Claudio Magris, un escritor sin fronteras ${ }^{1}$
}

\author{
Marco Martos Carrera \\ Universidad Nacional Mayor de San Marcos \\ mmartoscarrera@yahoo.com

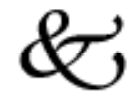

Señor Rector de la Universidad Nacional Mayor de San Marcos, Señores representantes de la Embajada de Italia en el Perú, Señores Vicerrectores, Señores Decanos, Señores profesores, alumnos y trabajadores, Señoras y señores:

La Universidad Nacional Mayor de San Marcos abre hoy sus brazos para recibir a Claudio Magris, un intelectual que honra a la lengua italiana y a la literatura mundial. Impenitente viajero por todos los rincones del planeta, hombre del mare nostrum romano y de la Europa contemporánea, ciudadano del mundo que hunde sus raíces en lo más profundo de la cultura propia, la de Trieste, Italia, y Europa Central, y entrega sus frutos, sus magníficas obras literarias que llegan a todos los lugares del mundo. Al hacerlo, el claustro rinde homenaje en Magris a toda la literatura italiana tan vigorosa desde que un poeta de Sicilia, Pier della Vigna, inventó un "pequeño sonidito", el soneto, hacia 1220 , que ha hecho fortuna en casi todas las lenguas del mundo, que honra a la literatura de Italia y la literatura escrita en castellano. Saludamos en Magris a la lengua de Dante, uno de los poetas mayores de todos los tiempos, a la lengua de Petrarca, pero especialmente a la lengua de Umberto Saba y de Italo Svevo, tan ligados a esa ciudad de encrucijadas que es Trieste, el lugar de nacimiento de Claudio Magris. Saludamos en Magris también al

1 Discurso de orden leído por el Dr. Marco Martos en la ceremonia del Doctorado Honoris Causa otorgado a Claudio Magris el 11 de diciembre de 2009. 
hombre ávido de la cultura del mundo, al traductor de Ibsen, al gran conocedor de los laberintos de la literatura escrita en alemán desde Kafka hasta Kleist y Schnitzer. Saludamos pues, a un intelectual, de primer rango en la literatura universal.

"Díganos unas pocas palabras sobre Claudio Magris" me dicen unos estudiantes y estas son las que ahora traigo con una imagen que me aconseja la poesía: Magris es al mismo tiempo el que hace y el que observa: tiene la curiosidad del aventurero, del científico, del niño, y es el que registra con precisión de orífice de las palabras, como un matemático, aquello que es importante para la especie humana. Se parece a Odiseo dirán los que leen sus libros de viajes, se semeja a Homero, completarán otros, aludiendo a sus escritos que penetran en lo más profundo del alma humana.

Claudio Magris es un escritor sin fronteras no solo por la marca y el sello que da Trieste a los que nacen en esa ciudad, ni tampoco solamente porque desde Italia ha sabido llegar a la cultura de todo el mundo, sino porque su literatura hace crujir sólidos conceptos literarios, algunos de los cuales vienen desde Aristóteles y que reforzados por la nueva retórica se enseñan en todas las universidades del mundo. Aunque este no es el lugar para discutirlo diremos que el concepto de novela contemporáneo que se forja en una tradición que viene desde Cervantes y llega hasta Vargas Llosa, tambalea frente a la literatura de Magris que se desliza con aparente facilidad entre la ficción y la no ficción en un mismo escrito y termina, de una manera práctica y no teórica, con una polémica que ha sacudido a la literatura de todo el siglo XX, aquello que Sartre llamó el compromiso de los intelectuales. Magris ha propuesto, con la sencillez de un maestro, que frente al dilema de qué defender en la sociedad contemporánea, solo nos queda escoger unos cuantos valores, los más sólidos, el derecho a la vida por ejemplo, y en eso no ceder ni pactar, en nombre de cualquier cultura particular. Y esa verdad de a puño puede y debe guiar el diálogo de las culturas y aquello que ha parecido penoso en estos tiempos, el diálogo entre las culturas particulares y la cultura universal. 
La mejor imagen que tenemos de la vida humana nos viene de Homero. De ese prodigioso aeda surge la idea hoy universal de que constantemente somos viajeros: desde el claustro materno al exterior, desde la casa a la escuela, de la universidad a los trabajos, de nuestro pueblo a la capital, de nuestro país a cualquier rincón del mundo, desde nuestra lengua a los idiomas diferentes. Siempre viajamos de lo conocido a lo desconocido, de lo que sabemos a lo que ignoramos, de lo que creemos a lo que soñamos. Y anhelamos siempre los regresos para encontrarnos con lo que amamos. Magris es un viajero por excelencia, muchos lo saben, pero no viaja solamente a pueblos diferentes, a ciudades diversas, viaja al fondo de la existencia humana en sus avatares históricos, viaja a las profundidades de las mentes desquiciadas y a la sanidad que emerge, como una hoja primaveral entre las grietas de la nieve.

De Homero nos viene justamente a hablar hoy día Magris. En su voz, la voz del viejo aeda atraviesa el tiempo en todos los navíos que han cruzado los mares con suave espuma de eternidad que salva a los náufragos y a los encantados por las sirenas. Por eso le decimos a Magris: Busquemos con Homero la poesía más escondida, y si acaso la encontremos, no cesemos de buscar porque cambia con el tiempo y es la misma en lo secreto. Ésta es la sabiduría: la palabra se semeja al hombre, es el hombre en el tiempo. La palabra es Proteo y cambia con el día y la noche. No acaba con la muerte, la sucede y queda en el aire, como quedó Homero. 